\title{
Preservation of olfaction in anterior midline skull base meningiomas: a comprehensive approach
}

\author{
Timothy H. Ung ${ }^{1}$, Alexander Yang ${ }^{1}$, Mohammed Aref ${ }^{1}$, Zach Folzenlogen ${ }^{1}$, Vijay \\ Ramakrishnan $^{1,2}$, and A. Samy Youssef ${ }^{1,2}$ \\ ${ }^{1}$ Department of Neurological Surgery, School of Medicine, University of Colorado, $12631 \mathrm{E}$. 17th \\ Ave., C307, Aurora, CO 80045, USA \\ ${ }^{2}$ Department of Otolaryngology, School of Medicine, University of Colorado, Aurora, CO 80045, \\ USA
}

\section{Abstract}

Background-Olfaction is an undervalued sense in neurosurgery. Attempted surgical resection of anterior cranial fossa meningiomas puts the olfactory pathway at risk. Preservation of olfaction may increase the postoperative quality of life. Objective assessment of olfaction may inform clinical decision-making and influence the selection of operative approaches for surgical resection.

Methods-We reviewed all patients who underwent surgical resection for midline anterior skull base meningiomas from July 1, 2014, through December 31, 2017. Patient demographics, tumor size, operative approach, pre- and postoperative deficits, and Simpson grade were collected and analyzed. Postoperative olfaction was assessed by clinical evaluation as well as objective evaluation using the University of Pennsylvania Smell Identification Test (UPSIT).

Results-Twenty-eight patients (10 male, 18 female) were included with an average age of 53.8 years (range 27-80 years). Twenty-six patients underwent craniotomy for resection, while 2 patients had endoscopic approaches. Average tumor volume was $402.1 \mathrm{~cm}^{3}\left(6.6-2507.7 \mathrm{~cm}^{3}\right)$. Preoperatively, five patients (17.8\%) presented with olfactory impairment. Objectively, 50\% of patients $(14 / 28)$ consented and completed the UPSIT. The average postoperative UPSIT score was 25.8/40 (9/40-38/40). Two patients not identified on clinical assessment alone demonstrated postoperative olfactory deficit on UPSIT (2/14).

Conclusion-There are limited published studies evaluating olfaction in patients who undergo skull-based approaches for anterior fossa meningiomas. Our series showed the highest olfaction preservation rate $(87.5 \%)$ using a comprehensive strategy and multitude of surgical approaches based on the olfactory function and tumor characteristics.

\footnotetext{
A. Samy Youssef Samy.Youssef@UCDenver.edu.

Conflict of interest The authors declare that they have no conflict of interest.

IRB approval 17-1887
}

Ethical approval All procedures performed in studies involving human participants were in accordance with the ethical standards of the institutional and/or national research committee (name of institute/committee) and with the 1964 Helsinki declaration and its later amendments or comparable ethical standards. For this type of study formal consent is not required.

Publisher's note Springer Nature remains neutral with regard to jurisdictional claims in published maps and institutional affiliations. 


\section{Keywords}

Anterior skull base; Meningioma; Meningiomas; Olfaction preservation; Olfactory groove; Tuberculum sella; Endoscopic; Transnasal

\section{Introduction}

The ability to smell allows an individual to experience their environment in a unique and personal way. Each person senses the world a little different and the ability to smell the world creates emotional relationships with other people, animals, and organic objects. Philosophers have led us to believe that vision is the primary sense in theorizing perception. The abstract nature of the secondary experience of olfaction and the debate between dispositionalism and projectivism as theories for olfaction lead to the long-standing neglect of the sense of smell. Neurosurgeons inherited such bias against olfaction and have been unsuccessful in prioritizing it in their surgical planning.

The olfactory epithelium is located superiorly in the nasal cavity, along the cribriform plate, the superior posterior nasal septum, inferiorly along the superior turbinate, and medially on the middle turbinate. The olfactory pathway is highly connected to the limbic system, and the ability to smell has been crucial for survival. It allows an individual to sense environmental hazards, as well as create a relationship with other individuals. It heightens our ability to taste food and is intimately involved in the development of our human traits, defense mechanisms, and personalities. Recent research has revealed lateralization of olfaction in humans, and in right-handed individuals, there is a right nostril and hemispheric predominance of olfactory processing for pleasant smells [1,2]. Unfortunately, approaches to the anterior cranial fossa put the olfactory pathway as risk-especially with traditional bifrontal craniotomy and bilateral transcribiform approaches to the anterior cranial fossa for resection of lesions such as olfactory groove meningioma (OGM) [3-10].

Anterior midline skull base meningiomas such as OGM, planum, and tuberculum sella are anatomically intimate to the olfactory apparatus. Tumor growth can cause compression of the olfactory nerves and may result in loss of olfaction bilaterally. Damage to the olfactory pathway may also occur during surgical resection secondary to retraction and dissection injury. This risk is increased during resection of giant-sized olfactory groove meningiomas where it may be difficult to visualize the olfactory structures. Endoscopic approaches have been associated with loss of olfaction except in a few reports [10].

Anterior midline skull base meningiomas require careful surgical planning with consideration of olfactory function and preservation of adjacent neurovascular structures. Thorough preoperative evaluation of olfaction and the possible lateralization, in addition to the tumor size, and location may help the surgeon in making better choices for management strategies. Contralateral olfactory preservation can be achieved with complete tumor resection through an open or an endoscopic approach [10].

To this date, there are limited published studies evaluating olfaction in patients who undergo open and endoscopic approaches for resection of anterior cranial fossa meningiomas $[6,11$, 
12]. In this study, we report the olfactory outcome after using a comprehensive strategy and multitude of surgical approaches based on the olfactory function. The UPSIT is used to objectively evaluate olfaction in patients with midline anterior skull base meningiomas.

\section{Methods}

\section{Patient selection}

Prior to initiation of this study, local Institutional Review Board approval was obtained to conduct a retrospective study evaluating olfaction in patients who underwent surgery for midline anterior skull base meningiomas from July 1, 2014, through December 31, 2017. Selection criteria for the study included patients' age more than 18 years and pathology consistent with a diagnosis of meningioma along the midline in the anterior cranial fossa. Only primary surgical patients were included in this study. Demographic data were collected for each patient and included: age, location of tumor, preoperative tumor volume, extent of surgical resection, and pre- and postoperative olfaction.

All patients were evaluated by magnetic resonance (MR) imaging before surgery as well as immediately within the postoperative period (within $24 \mathrm{~h}$ ). Preoperative tumor volume was calculated by the maximal height, length, and width. Postoperative resection volume and Simpson grade [13] were determined by both the neurosurgeon(s) and confirmed by postoperative imaging. All patients underwent surgical resection by either craniotomy, endoscopic, or a combination of the surgical techniques. Final tumor pathology and World Health Organization grading were completed by a neuropathologist.

\section{Olfaction assessment}

Preoperative olfaction was clinically determined as documented in the patients' electronic medical record. After patient selection, patients were sent the University of Pennsylvania Smell Identification Test (UPSIT) [5]. Postoperative olfaction was both assessed clinically and objectively. Clinical assessment was conducted during clinic visit. A more comprehensive objective assessment was done by using the UPSIT. UPSITs were scored using the provided scorecard [5]. Student's $t$ test and an Analysis of Variance (ANOVA) were used to assess demographic factors such as sex, age, and Simpson grade. A Pearson correlation was used to assess for significance as related to tumor volumes and UPSIT scores. Statistical significance was determined by a $P$ value $<0.05$. Statistical analysis was performed using PRISM GraphPad (La Jolla, CA, USA).

\section{Surgical approach}

The surgical approach was selected based on olfactory function and tumor size. Tumor size is based on the largest anteroposterior tumor diameter according to Mohr classification [14].

1. Small lesions (less than $2 \mathrm{~cm}$ ):

Intact olfaction: keyhole unilateral approach with or without endoscopic assistance

Lost olfaction: endonasal endoscopic approach In the rare case of an olfactory groove meningioma with a unilateral cribriform plate origin, we perform a 
unilateral endoscopic transcribriform approach with preservation of the contralateral olfactory function [10].

2. Moderate size lesions $(2-4 \mathrm{~cm})$ :

Intact olfaction: unilateral fronto-orbital approach with or without endoscopic assistance

Lost olfaction: endonasal endoscopic approach or unilateral fronto-orbital approach

3. Large to giant lesions (more than $4 \mathrm{~cm}$ ):

Unilateral tailored fronto-orbital approach [15] regardless of olfactory function

\section{Results}

\section{Study demographics}

In total, 28 patients were identified and included in this study (Table 1). There were 10 male and 18 female patients with and average age of 53.8 years (range 23-75 years). Preoperatively, the average tumor size was $402.13 \mathrm{~cm}^{3}$ ranged from 6.6 to $2507.7 \mathrm{~cm}^{3}$. Of the patients that presented with anterior cranial fossa meningioma, two patients underwent purely endoscopic resection and 26 patients underwent craniotomy and endoscopic-assisted surgical resection. Patients initially presented with visual impairment $(75 \%, 21 / 28)$ as the most common initial manifestation. Preoperative steroids were given to $11 / 28(30.2 \%)$ of the patients and 3/28 (10.7\%) of patients underwent preoperative endoscopic transnasal or transcaruncular ligation of ethmoidal arteries prior to planned craniotomy for neurosurgical resection [16].

\section{Outcomes}

Histopathological analysis indicated WHO grade II meningioma in 2 patients and WHO I meningioma in the remaining 26 patients. Postoperative complications were observed in a single patient who experienced syndrome of inappropriate antidiuretic hormone secretion (SIADH). Simpson grading was used to classify extent of meningioma tumor resection. Overall, our cohort had 9 patients with Simpson grade I, 13 patients with Simpson grade II, and 6 patients with Simpson grade IV tumor resection as determined by intraoperative reports and postoperative image evaluation (Table 1). Near total resection was favored if tumor was adherent to neurovascular structures namely anterior cerebral arteries complex or olfactory bulbs with intact olfaction.

\section{Olfactory function}

Preoperative olfaction was determined clinically during preoperative clinical evaluation. Preoperative olfactory impairment was initially present in five patients based on preoperative clinical examination. There was no statistically significant difference when comparing male versus female patients in preoperative olfactory dysfunction, $P$ value 0.33 . There was also no statistical difference in age-related preoperative olfactory dysfunction, $P$ value 0.22 . Patients who presented with olfactory dysfunction had larger lesions when compared with those with intact sensation, $P$ value 0.03 . The anatomical tumor locations were as follows: nine planum 
sphenoidale, eight tuberculum sellae, seven olfactory grooves, two clinoidals, and two midline basal convexities. Among the five patients with smell dysfunction, three had planum sphenoidale and two had olfactory groove meningiomas (Table 2).

Postoperative olfaction was assessed both in the clinical setting as well as by UPSIT. Clinically, one patient with tuberculum sellae meningioma acquired new postoperative olfactory deficit. Four patients with tuberculum sellae meningiomas who initially presented with olfactory deficit continued to have persistent olfactory deficit after surgical resection and 1 patient had improvement in his ability to smell based on clinical assessment. In 23 patients without preoperative olfactory deficit, olfactory preservation was achieved in 22 patients, a surgical olfactory preservation rate of $95.7 \%$ based on clinical evaluation. In patients who presented with diminished olfaction, $1 / 5$ (20\%) of patients had improvement of their olfaction.

All patients included in this study were also contacted and asked to participate in a postoperative evaluation of olfaction. Of the 28 that were contacted, 14 consented to and returned their UPSIT (50\%). The average postoperative UPSIT score was 25.8/40 (range 938/40). When Simpson grading was included, no statistical significance was observed in terms of postoperative UPSIT scores, $P$ value 0.96 . Male patients had decreased UPSIT (12.0/40) postoperative scores when compared with women (27.8/40), $P$ value 0.01 . Additionally, a larger tumor volume was significantly correlated with postoperative UPSIT scores, $P$ value 0.01 . However, tumor location did not impact UPSIT scores. Preoperative steroid administration was not associated with a statistically significant difference in UPSIT scores $(P$ value 0.36$)$.

Additionally, postoperative clinical assessment was compared with objective UPSIT results. In our 14/28 patients who completed their UPSIT, two patients were noted to have postoperative anosmia on UPSIT scoring that were not found on clinical assessment alone. The average UPSIT score of these patients was 9.5/40 and an UPSIT score $\leq 10$ is considered a failing score (Table 2).

\section{Discussion}

Olfaction assessment and preservation should be a major goal in anterior midline skull base meningiomas. A comprehensive approach that includes an UPSIT and a tailored surgical approach selection based on olfactory function and tumor size can improve olfactory outcomes as reported in our study.

\section{Published olfactory outcomes}

Very few studies reported postoperative olfactory outcomes after anterior skull base meningiomas resection, and it is often not clear if a comprehensive smell test was used. Current literature suggests olfactory preservation rates between 24.4 and $55 \%$ in patients undergoing anterior skull base meningioma resections [3, 6, 12, 17]. Important factors include tumor sizes less than $4 \mathrm{~cm}$, preoperative olfactory function and surgical approaches such as fronto-lateral approaches have been correlated to increased postoperative olfaction rates $[6,17]$. All prior studies recommend a conscious effort in saving olfaction in patients 
with either normal or diminished preoperative olfaction. Radiosurgery has evolved as a valid treatment option for small- to medium-sized tumors in patients with intact olfaction. However, there is a paucity of reports that comprehensively evaluate olfaction after radiosurgery. Gande et al. retrospectively reported subjective assessment of olfaction after gamma knife treatment with a median clinical and radiographic follow-up period of 76 and 65 months respectively. There was no patients' reported loss of olfaction in their series [18].

\section{Our case series}

Our study included 28 patients and had a greater predominance of females versus males. In patients with preoperative anosmia, risk factors included location and size of the tumor. All of our five patients with preoperative anosmia had planum sphenoidale or olfactory groove meningioma. Interestingly, $29.4 \%$ of patients with lesions located within either planum sphenoidale or olfactory groove had olfactory dysfunction. Not surprisingly, tumor size had a significant association with olfactory pathology. Likely, a larger tumor may cause adjacent compression of the olfactory bulbs and cortical pathways. Patient sex and age had no effect on preoperative olfactory disruption.

Postoperative evaluation included both a clinical assessment as well as an objective marker for olfaction - the UPSIT (Sensonics International, Haddon Heights, NJ, USA). On clinical evaluation alone, only one of 23 patients without preoperative olfactory dysfunction went on to develop new postoperative deficit. Therefore, based on clinical evaluation alone, we were able to preserve olfaction in $95.7 \%$ of our surgical patients who did not present with olfactory deficit. One patient had overall improvement in their ability to smell postoperative and four patients continued to have olfactory dysfunction on clinical evaluation-a clinical improvement in $20 \%$ of patients with preoperative deficit.

\section{Comprehensive assessment of olfaction}

As an objective assessment of postoperative anosmia, we utilized the UPSIT. The UPSIT was chosen for its simplicity in administration and non-bias scoring system. Briefly, the UPSIT test is composed of 40 "scratch and sniff" questions separated into four booklets. All questions contain four answer choices in a multiple-choice format. Patients then select an answer for each of the 40 items (20 familiar and 20 unfamiliar smells) and the total is scored based on an answer key provided. Scores are out of 40 and a score of less than 10/40 would be considered "guessing" or inability to smell [5]. Whereas clinical assessment of olfaction often leads to a binary and subjective classification, the UPSIT is a reproducible method that allows for a range of scoring and long-term patient assessment.

In patients that completed the UPSIT study, the average score was $25.8 / 40$ with a range from 9 to 38 out of 40. Postoperative risk factors associated with postoperative anosmia included male patient and tumor size. Postoperative UPSIT scores for men averaged less than $1 / 2$ of women scores, 12.0 versus 27.8 respectively. Furthermore, patients with larger tumor had decreased postoperative UPSIT score. This association was also seen in patients who presented with preoperative dysfunction. Likely, this significant finding can be attributed to preoperative irreversible damage to the olfactory pathway. Similarly, patients who presented with olfactory dysfunction continued to have increased risk of continued dysfunction after 
surgical resection. Tumor location and preoperative treatment with steroids did not have a significant association with postoperative UPSIT scores. Significantly, UPSIT assessment identified 2 patients with postoperative deficits not otherwise clinically identified and allowed our team to identify three total patients with postoperative olfactory dysfunction, an olfactory preservation rate of $87.5 \%$ (21/24). To the best of our knowledge, this is the highest rate of preservation of olfaction in anterior midline skull base meningiomas to date. We believe that this is attributed to our comprehensive management algorithm that is based on olfactory function and tumor characteristics (Fig. 1). Our multitude of surgical approaches focused on the anatomical preservation of the olfactory apparatus starting from the nasal cavity all the way to the entorhinal cortex in patients with intact olfaction. For example, a unilateral transcribriform approach was utilized to preserve the contralateral olfactory apparatus in a small olfactory groove meningioma of unilateral origin (Fig. 2). The anatomical preservation of the olfactory bulbs and tracts in an extra-arachnoidal fashion was pursued in transcranial approaches even for giant tumors. We believe that this preserves the nerve vascularity and contribute to a better functional outcome (Fig. 3). For giant tumors, we performed a tailored unilateral fronto-orbital approach [15] rather than a bifrontal approach. We make an effort to preserve at least the contralateral olfactory nerve in these giant tumors (Fig. 4). As previously reported, unilateral approaches have been associated with higher olfaction preservation [6].

\section{Study limitation and future direction}

Our study is limited by the overall study size, patients' consenting to UPSIT evaluation, retrospective nature, and the absence of preoperative UPSIT assessment. However, we feel strongly about introducing and promoting the concept of "olfaction first" through our cohort data. Future studies will include a larger population that may allow us to fully elucidate risk factors for preoperative and postoperative anosmia and the ability to preserve olfaction in skull base meningioma patients.

\section{References}

1. Brand G, Jacquot L (2001) Quality of odor and olfactory lateralization processes in humans. Neurosci Lett 316:91-94. 10.1016/s0304-3940(01)02375-8 [PubMed: 11742723]

2. Savic IB, Hans B (2000) Right-nostril dominance in discrimination of unfamiliar, but not familiar, odours. Chem Senses 25:517-523 [PubMed: 11015323]

3. Banu MA, Mehta A, Ottenhausen M, Fraser JF, Patel KS, Szentirmai O, Anand VK, Tsiouris AJ, Schwartz TH (2016) Endoscope-assisted endonasal versus supraorbital keyhole resection of olfactory groove meningiomas: comparison and combination of 2 minimally invasive approaches. J Neurosurg 124:605-620. 10.3171/2015.1.JNS141884 [PubMed: 26274992]

4. de Almeida JR, Carvalho F, Vaz Guimaraes Filho F, Kiehl TR, Koutourousiou M, Su S, Vescan AD, Witterick IJ, Zadeh G, Wang EW, Fernandez-Miranda JC, Gardner PA, Gentili F, Snyderman CH (2015) Comparison of endoscopic endonasal and bifrontal craniotomy approaches for olfactory groove meningiomas: a matched pair analysis of outcomes and frontal lobe changes on MRI. J Clin Neurosci: Official Journal of the Neurosurgical Society of Australasia 22:1733-1741. 10.1016/ j.jocn.2015.03.056

5. Doty RL, Shaman P, Kimmelman CP, Dann MS (1984) University of Pennsylvania Smell Identification Test: a rapid quantitative olfactory function test for the clinic. Laryngoscope 94:176178 [PubMed: 6694486] 
6. Jang WY, Jung S, Jung TY, Moon KS, Kim IY (2013) Preservation of olfaction in surgery of olfactory groove meningiomas. Clin Neurol Neurosurg 115:1288-1292. 10.1016/j.clineuro. 2012.12.004 [PubMed: 23312758]

7. Koutourousiou M, Fernandez-Miranda JC, Wang EW, Snyderman CH, Gardner PA (2014) Endoscopic endonasal surgery for olfactory groove meningiomas: outcomes and limitations in 50 patients. Neurosurg Focus 37:E8

8. Ramakrishnan VR, Suh JD, Chiu AG, Palmer JN (2011) Septal dislocation for endoscopic access of the anterolateral maxillary sinus and infratemporal fossa. Am J Rhinol Allergy 25:128-130. 10.2500/ajra.2011.25.3559 [PubMed: 21679518]

9. Rosen MR, Rabinowitz MR, Farrell CJ, Schaberg MR, Evans JJ (2014) Septal transposition: a novel technique for preservation of the nasal septum during endoscopic endonasal resection of olfactory groove meningiomas. Neurosurg Focus 37:E6 10.3171/2014.7.FOCUS14308

10. Youssef AS, Sampath R, Freeman JL, Mattingly JK, Ramakrishnan VR (2016) Unilateral endonasal transcribriform approach with septal transposition for olfactory groove meningioma: can olfaction be preserved? Acta Neurochir 158:1965-1972 [PubMed: 27562683]

11. Greig SR, Cooper TJ, Sommer DD, Nair S, Wright ED (2016) Objective sinonasal functional outcomes in endoscopic anterior skull-base surgery: an evidence-based review with recommendations. Int Forum Allergy Rhinol 6:1040-1046. 10.1002/alr.21760 [PubMed: 27389868]

12. Ottenhausen M, Rumalla K, Alalade AF, Nair P, La Corte E, Younus I, Forbes JA, Ben Nsir A, Banu MA, Tsiouris AJ, Schwartz TH (2018) Decision-making algorithm for minimally invasive approaches to anterior skull base meningiomas. Neurosurg Focus 44:E7 10.3171/2018.1.FOCUS17734

13. Adegbite AB, Khan MI, Paine KWE, Tan LK (1983) The recurrence of intracranial meningiomas after surgical-treatment. J Neurosurg 58:51-56. 10.3171/jns.1983.58.1.0051 [PubMed: 6847909]

14. Li MS, Portman SM, Rahal A, Mohr G, Balasingam V (2014) The lion's mane sign: surgical results using the bilateral fronto-orbito-nasal approach in large and giant anterior skull base meningiomas. J Neurosurg 120:315-320. 10.3171/2013.11.JNS13552 [PubMed: 24329027]

15. Downes AE, Freeman JL, Ormond DR, Lillehei KO, Youssef AS (2015) Unilateral tailored frontoorbital approach for giant olfactory groove meningiomas: technical nuances. World Neurosurg 84:1166-1173. 10.1016/j.wneu.2015.05.011 [PubMed: 25986205]

16. Ung TH, Waziri AE, Ramakrishnan VR (2014) Preoperative ethmoid artery ligation facilitates resection of large sub-frontal meningiomas. Am J Otolaryngol 35:424-426. 10.1016/j.amjoto. 2014.01.003 [PubMed: 24499924]

17. Bassiouni H, Asgari S, Stolke D (2007) Olfactory groove meningiomas: functional outcome in a series treated microsurgically. Acta Neurochir 149:109-121; discussion 121. 10.1007/ s00701-006-1075-z [PubMed: 17180303]

18. Gande A, Kano H, Bowden G, Mousavi SH, Niranjan A, Flickinger JC, Lunsford LD (2014) Gamma knife radiosurgery of olfactory groove meningiomas provides a method to preserve subjective olfactory function. J Neuro-Oncol 116:577-583. 10.1007/s11060-013-1335-8 
Anterior Midline Skull Base Meningioma

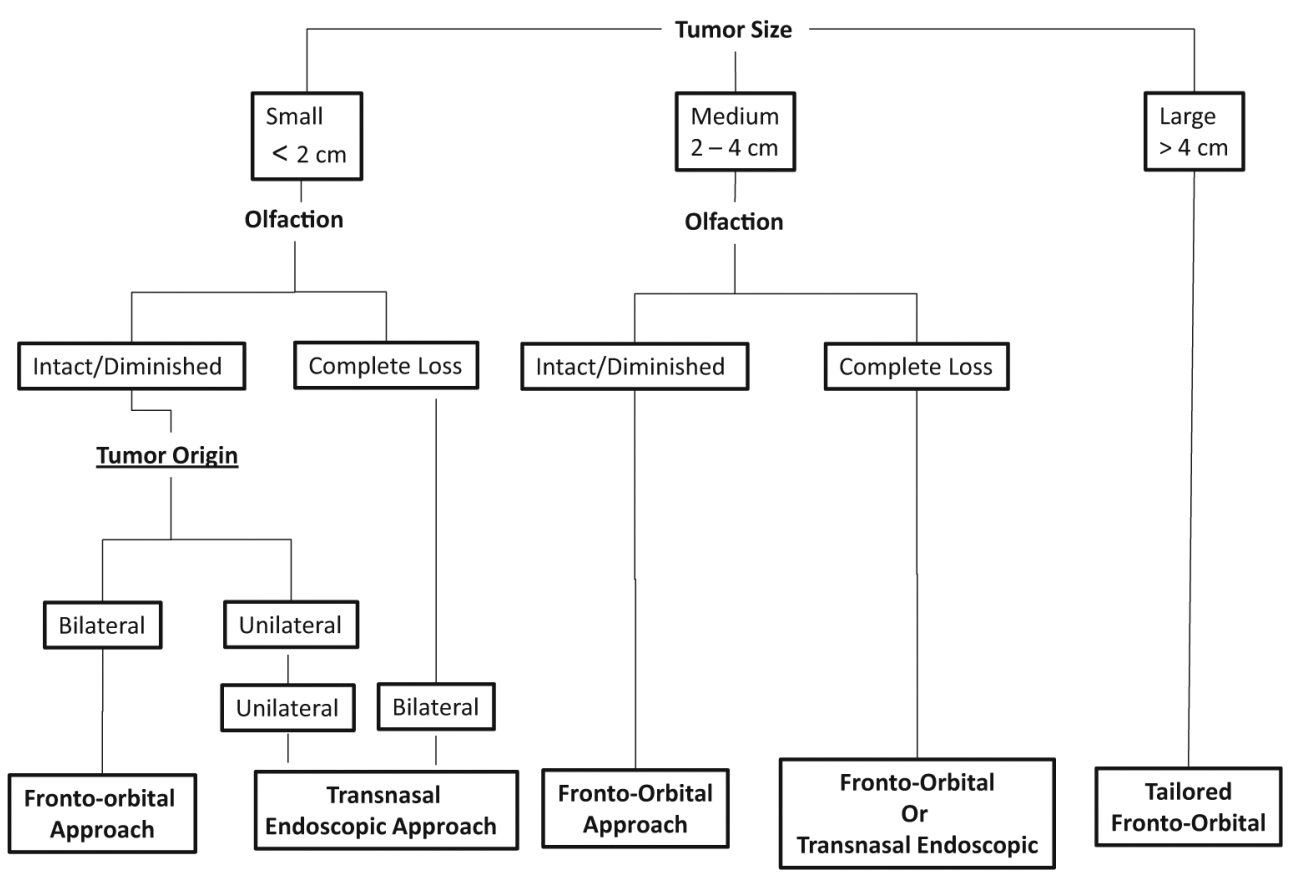

Fig. 1.

Surgical management of anterior skull base meningiomas 


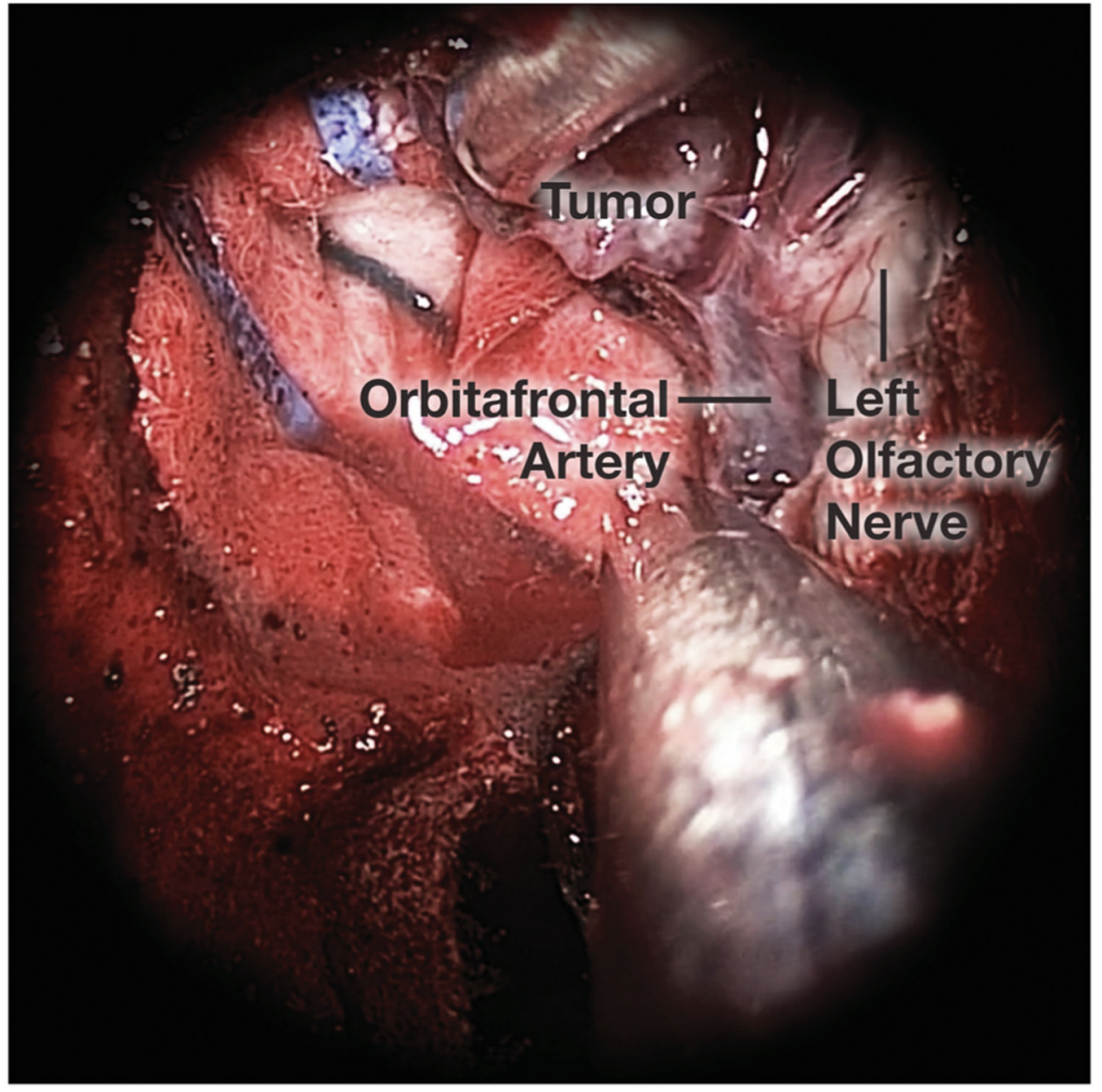

Fig. 2.

Unilateral right transcribrifrom approach with direct visualization of the left-sided olfactory apparatus and optic tract 


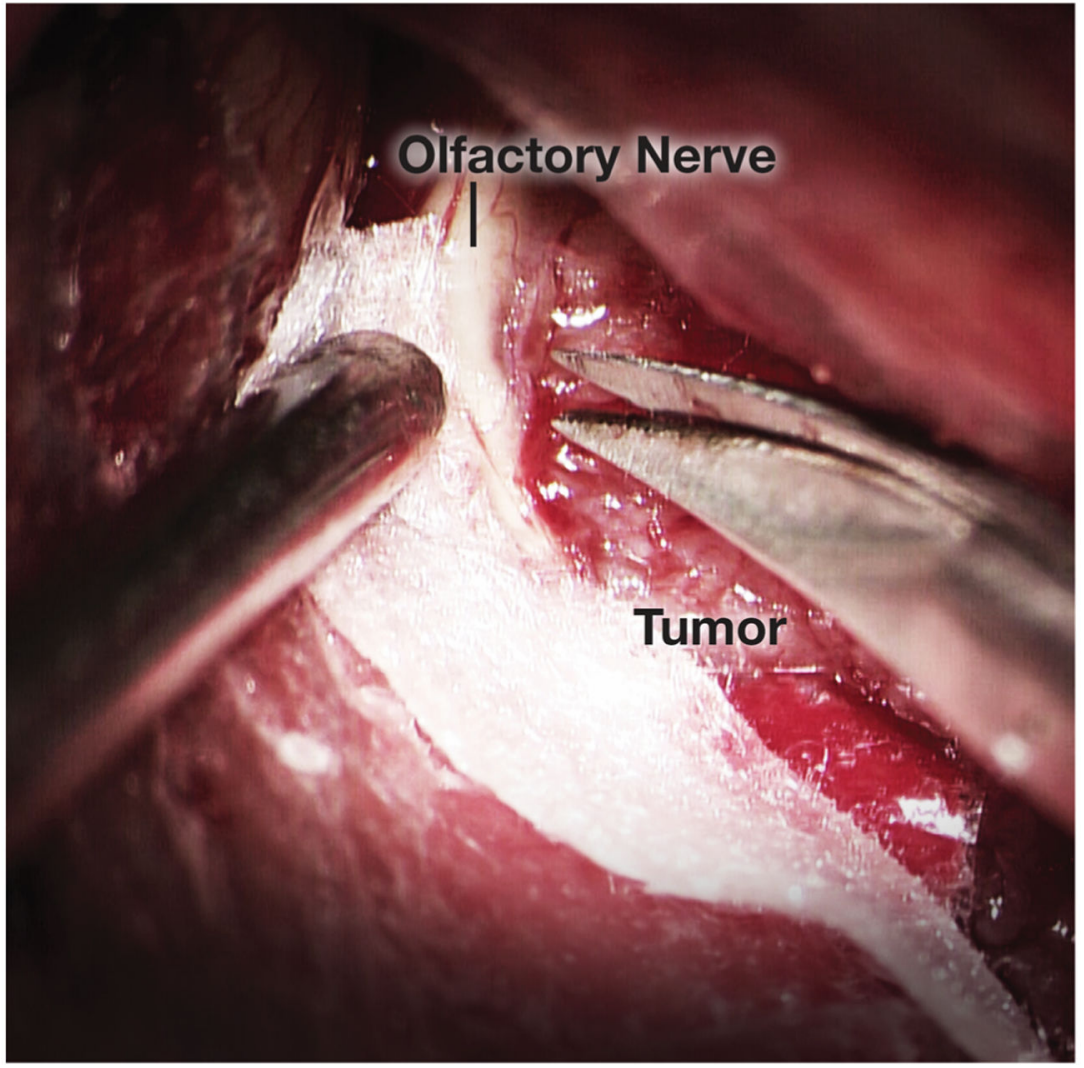

Fig. 3.

Direct microscopic view of the olfactory tract with arachnoid preservation during a meningioma resection 

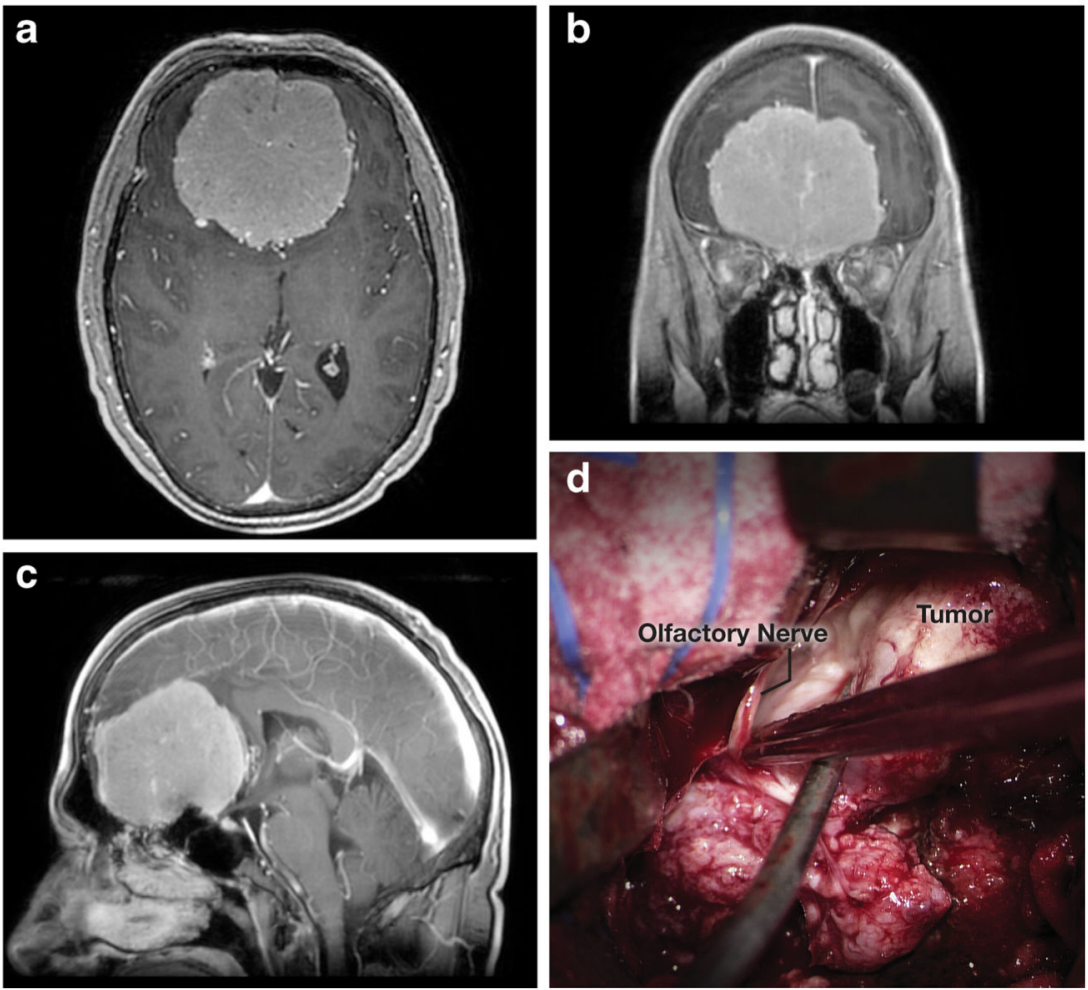

Fig. 4.

A 61-year-old male patient with a giant olfactory groove meningioma, a-c MRI T1 contrasted images demonstrate a $70 \mathrm{~mm} \times 63 \mathrm{~mm} \times 69 \mathrm{~mm}$ lesion in the anterior cranial fossa. d A tailored unilateral fronto-orbital approach with preservation of the contralateral olfactory apparatus 


\section{Table 1}

Demographic data

\begin{tabular}{ll}
\hline Demographic data & \\
\hline Total patients & 28 \\
Male & 10 \\
Female & 18 \\
Age & 53.8 years; range $(23-75$ years $)$ \\
Tumor characteristics & \\
Size & $402.13 \mathrm{~cm}^{3}$; range $\left(6.6-2507.7 \mathrm{~cm}^{3}\right)$ \\
WHO grade & \\
I & 26 \\
II & 2 \\
Tumor location & \\
Planum sphenoidale & 9 \\
Tuberculum sellae & 8 \\
Olfactory groove & 7 \\
Clinoidal & 2 \\
Midline basal convexity & 2 \\
Simpson grade & \\
Grade I & 9 \\
Grade II & 13 \\
Grade III & 0 \\
Grade IV & 6 \\
\hline
\end{tabular}




\section{롤}

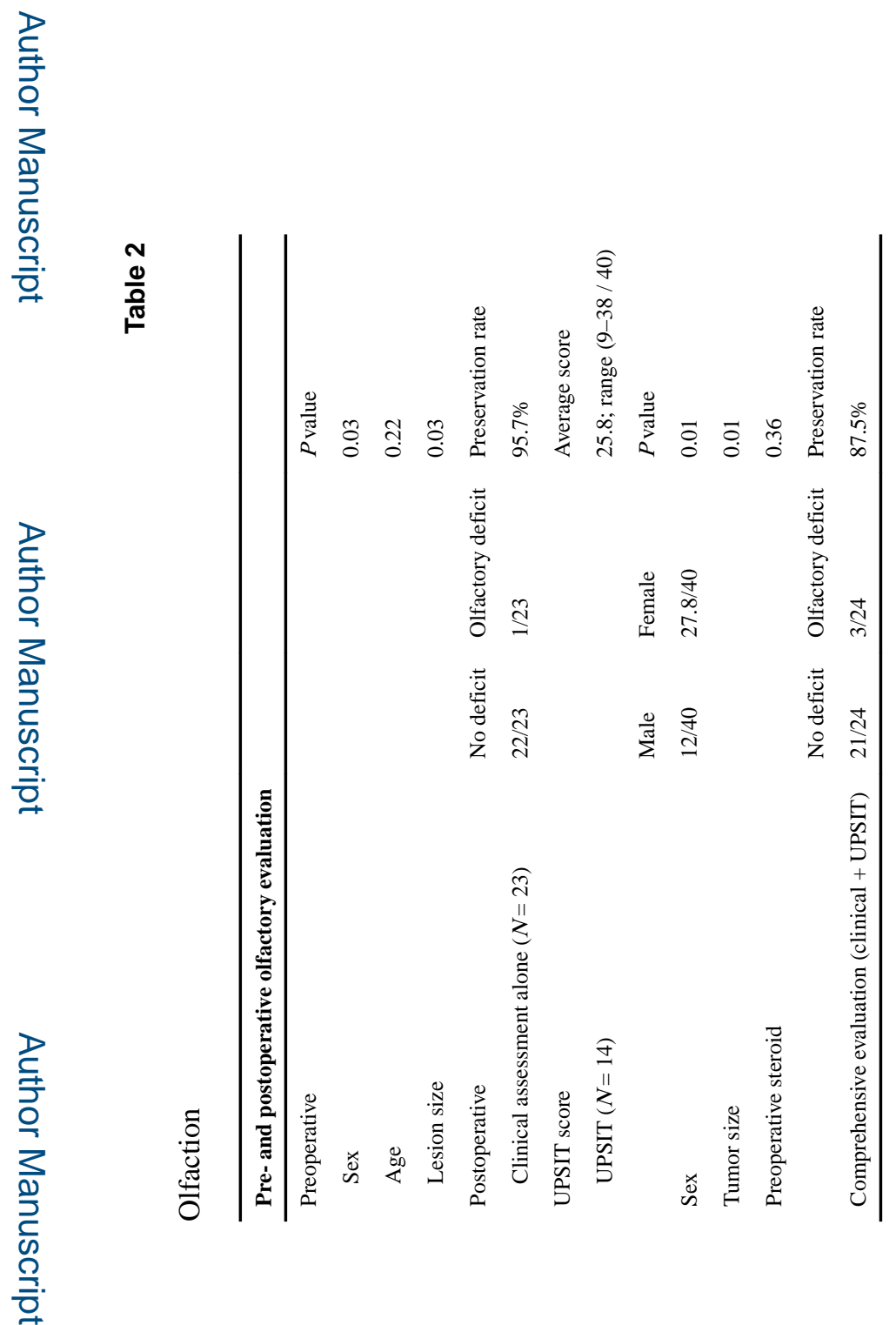

Acta Neurochir (Wien). Author manuscript; available in PMC 2020 April 01. 